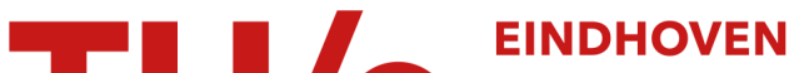 \\ UNIVERSITY OF \\ TECHNOLOGY
}

\section{Efficiency loss processes in hyperfluorescent OLEDs}

\section{Citation for published version (APA):}

Gottardi, S., Barbry, M., Coehoorn, R., \& van Eersel, H. (2019). Efficiency loss processes in hyperfluorescent OLEDs: a kinetic Monte Carlo study. Applied Physics Letters, 114(7), [073301].

https://doi.org/10.1063/1.5079642

DOI:

10.1063/1.5079642

Document status and date:

Published: 18/02/2019

\section{Document Version:}

Publisher's PDF, also known as Version of Record (includes final page, issue and volume numbers)

\section{Please check the document version of this publication:}

- A submitted manuscript is the version of the article upon submission and before peer-review. There can be important differences between the submitted version and the official published version of record. People interested in the research are advised to contact the author for the final version of the publication, or visit the $\mathrm{DOI}$ to the publisher's website.

- The final author version and the galley proof are versions of the publication after peer review.

- The final published version features the final layout of the paper including the volume, issue and page numbers.

Link to publication

\section{General rights}

Copyright and moral rights for the publications made accessible in the public portal are retained by the authors and/or other copyright owners and it is a condition of accessing publications that users recognise and abide by the legal requirements associated with these rights.

- Users may download and print one copy of any publication from the public portal for the purpose of private study or research.

- You may not further distribute the material or use it for any profit-making activity or commercial gain

- You may freely distribute the URL identifying the publication in the public portal.

If the publication is distributed under the terms of Article 25fa of the Dutch Copyright Act, indicated by the "Taverne" license above, please follow below link for the End User Agreement:

www.tue.nl/taverne

Take down policy

If you believe that this document breaches copyright please contact us at:

openaccess@tue.nl

providing details and we will investigate your claim. 


\section{Efficiency loss processes in hyperfluorescent OLEDs: A kinetic Monte Carlo study}

Cite as: Appl. Phys. Lett. 114, 073301 (2019); https://doi.org/10.1063/1.5079642

Submitted: 01 November 2018 . Accepted: 28 January 2019. Published Online: 20 February 2019

S. Gottardi (D), M. Barbry, R. Coehoorn (D), and H. van Eersel
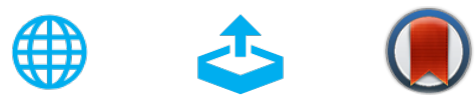

View Online

Export Citation

CrossMark

\section{ARTICLES YOU MAY BE INTERESTED IN}

Triplet-triplet annihilation in a thermally activated delayed fluorescence emitter lightly doped in a host

Applied Physics Letters 113, 083301 (2018); https://doi.org/10.1063/1.5025870

Enhanced near-infrared electroluminescence from a neodymium complex in organic lightemitting diodes with a solution-processed exciplex host

Applied Physics Letters 114, 033301 (2019); https://doi.org/10.1063/1.5054721

Improving blue quantum dot light-emitting diodes by a lithium fluoride interfacial layer Applied Physics Letters 114, 071101 (2019); https://doi.org/10.1063/1.5087102

\section{Applied Physics Reviews} Now accepting original research

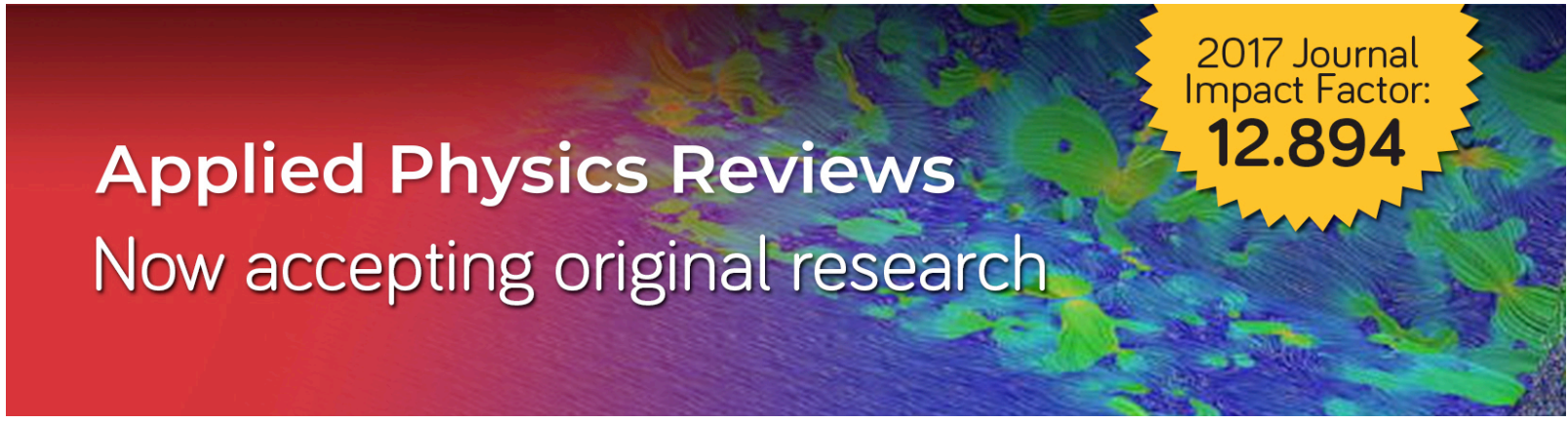




\title{
Efficiency loss processes in hyperfluorescent OLEDs: A kinetic Monte Carlo study
}

\author{
Cite as: Appl. Phys. Lett. 114, 073301 (2019); doi: 10.1063/1.5079642 \\ Submitted: 1 November 2018 - Accepted: 28 January 2019 . \\ Published Online: 20 February 2019; Publisher Error Corrected 26 February 2019

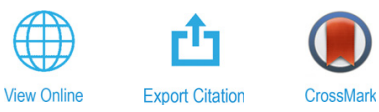

\author{
S. Gottardi, ${ }^{1, a)}$ (iD M. Barbry, ${ }^{1}$ R. Coehoorn, ${ }^{2}$ (D) and H. van Eersel ${ }^{1}$
}

\author{
AFFILIATIONS \\ ${ }^{7}$ Simbeyond B.V., P.O. Box 513, NL-5600 MB Eindhoven, The Netherlands \\ ${ }^{2}$ Department of Applied Physics and Institute for Complex Molecular Systems, Eindhoven University of Technology, P.O. Box 513, \\ NL-5600 MB Eindhoven, The Netherlands \\ a) stefano.gottardi@simbeyond.com
}

\begin{abstract}
In hyperfluorescent OLEDs, fluorescent emitter molecules are sensitized by molecules utilizing thermally activated delayed fluorescence (TADF). In principle, obtaining an internal quantum efficiency (IQE) approaching 100\% combined with a small IQE roll-off should be feasible. However, the actual device performance depends on the balance between the transfer of singlet and triplet excitons from the TADF emitters to the fluorescent molecules and on the role of excitonic loss processes. Here, we study these factors governing the IQE using kinetic Monte Carlo simulations, for prototypical OLEDs based on the green TADF emitter (2s,4r,6s)-2,4,5,6-tetrakis(3,6-dimethyl-9H-carbazol-9-yl)isophthalonitrile (4CzIPN-Me) and the yellow fluorescent emitter 2,8di-tert-butyl-5,11-bis(4-tert-butylphenyl)-6,12-diphenyltetracene. Making use of the experimental photophysical interaction rates, the simulated voltage versus current density characteristics and IQE roll-off agree well with experiment. The simulations show that the IQE can be enhanced by carefully avoiding the formation of charge-transfer excitons.
\end{abstract}

Published under license by AIP Publishing. https://doi.org/10.1063/1.5079642

In organic light-emitting diodes (OLEDs) utilizing thermally activated delayed fluorescence (TADF), emission takes place from molecules or molecular pairs on which weakly bound electron-hole pairs reside, with such a small splitting between the singlet and triplet states that non-emissive triplet states can be thermally converted to the emissive singlet state. This provides the possibility to obtain for TADF-based OLEDs a near$100 \%$ internal quantum efficiency (IQE), even if under electrical operation a sizeable fraction of the generated excited states is a triplet. ${ }^{1-8}$ However, for molecules with a small singlet-triplet gap, the singlet exciton transition dipole moment is in general relatively small. As a result, the emissive lifetime can be $0.1-1 \mu \mathrm{s}$, approaching that of phosphorescent Ir-based metal-organic emitters for which bimolecular loss processes such as tripletpolaron quenching (TPQ) and triplet-triplet annihilation (TTA) lead to a considerable decrease in the IQE at a high current density ("roll-off"). ${ }^{9-11}$ This could explain why TADF-based OLEDs also show a significant IQE roll-off. Moreover, the extended nature of the charge-transfer (CT) type exciton wavefunctions leads to a relatively large width of the emission spectrum that is undesirable for display applications. In order to reduce or even eliminate these disadvantages, Nakanotani et al. have proposed a next-generation of OLEDs in which TADF emitters are utilized as sensitizers of fluorescent dye molecules. ${ }^{12}$ The mechanism has been called "hyperfluorescence" (HF), the term used in this paper, or "TADF-assisted fluorescence" (TAF). ${ }^{13-18}$

In this paper, we study the functioning of HF-OLEDs using kinetic Monte Carlo (KMC) simulations. We focus on prototypical devices of the type studied extensively by Furukawa et al., with external quantum efficiencies at small current densities close to $20 \%{ }^{13}$ For these devices, accurate photophysical data, experimental device characteristics, and a comparison with the performance of related fluorescent and TADF-OLEDs are available. For phosphorescent OLEDs, KMC simulations have been used successfully to unravel the effects on the roll-off of the layer and energy level structure, the composition of the emissive layer (EML), the factors affecting the electron and hole transport, and the TPQ and TTA rates. ${ }^{19-22}$ For the HF-OLEDs studied, the simulations reveal how the IQE is sensitively determined by the stability of CT exciton states between the TADF and fluorescent guest molecules and by the balance between the Förstertype singlet exciton transfer from the TADF molecules to the 
fluorescent dye molecules and the direct generation of excitons on the fluorescent molecules.

Figure 1(a) shows the layer and energy level structure of the devices studied. The emissive layer (EML) consists of the host material 3,3-di(9H-carbazol-9-yl)biphenyl (mCBP), $6.3 \mathrm{~mol}$ \% of the TADF material $(2 \mathrm{~s}, 4 \mathrm{r}, 6 \mathrm{~s})-2,4,5,6$-tetrakis(3,6-dimethyl-9Hcarbazol-9-yl)isophthalonitrile (4CzIPN-Me), and $0.65 \mathrm{~mol}$. \% of the fluorescent emitter 2,8-di-tert-butyl-5,11-bis(4-tert-butylphenyl)-6,12-diphenyltetracene (TBRb). Our study also includes a comparison with the pure-TADF parent system and with fluorescent devices (F-OLEDs) with an EML consisting of $0.65 \mathrm{~mol}$. $\%$ TBRb in mCBP. In all cases, 4,4' -cyclohexylidenebis[N,N-bis(4methylphenyl)benzenamine] (TAPC) was used as the hole transport material, 2,4,6-tris(biphenyl-3-yl)-1,3,5-triazine (T2T) was used as the hole blocking material, and tris(8-hydroxyquinolinato)aluminum ( $\mathrm{Alq}_{3}$ ) was used as the electron transport material. These layer structures are identical to those studied experimentally in Ref. 13. The injection from doped injection layers is simulated by assuming a metal-organic interface with a small $(0.2 \mathrm{eV})$ injection barrier. Figure 1(b) shows the exciton energies for the TADF and fluorescent emitters and the energy of $4 \mathrm{CzIPN}-$ $\mathrm{Me}$ (electron):TBRb(hole) charge-transfer (CT) excitons. The figure also shows the main excitonic transfer processes affecting the efficiency roll-off, including dissociation of a singlet on TBRb to a CT-state exciton, followed by intersystem crossing and transfer of the CT-state triplet to TBRb.

Mechanistic simulations of the device performance at $300 \mathrm{~K}$ have been carried out using the KMC simulation tool Bumblebee, ${ }^{19,20,23}$ using the material parameters available from the literature, and refined and extended in the following manner. The values of the highest occupied molecular orbital energy (HOMO) energies, $\mathrm{E}_{\mathrm{HOMO}}$, were taken from photoelectron yield spectroscopy. 12,13 Often, the lowest unoccupied molecular orbital (LUMO) energy, $E_{\text {LUMO }}$, is estimated by adding the optical gap energy to $\mathrm{E}_{\mathrm{HOMO}}$. However, due to the singlet exciton binding energy, $E_{\mathrm{S}, \mathrm{b}}$, the HOMO-LUMO gap is for small-molecule materials typically $0.75-1.25 \mathrm{eV}$ larger than the optical gap. ${ }^{24,25}$ The gaps used in this work include this contribution. From inverse photoelectron spectroscopy, ${ }^{25,26}$ we take $E_{\mathrm{S}, \mathrm{b}}=1.21 \mathrm{eV}$ and $0.61 \mathrm{eV}$ for $\mathrm{Alq}_{3}$ and $4 \mathrm{CzIPN}-\mathrm{Me}$, respectively. For the other materials, we take $E_{\mathrm{S}, \mathrm{b}}=1.0 \mathrm{eV}$. The small value for $4 \mathrm{CzIPN}-\mathrm{Me}$ is consistent with the CT character of the excitons. From the simulations, the formation of CT-excitons with the electron and the hole on nearest-neighbor molecules is found to play an important role. As the intersite distance assumed is $1 \mathrm{~nm}$ and the relative dielectric constant is 3 , the binding energy of such excitons is $0.48 \mathrm{eV}$. As an example, Fig. 1(b) shows the energy $(2.11 \mathrm{eV})$ of $4 \mathrm{CzIPN}-\mathrm{Me}$ (electron):TBRb(hole) CT-excitons, which affects the dissociation probability of singlets on TBRb (see below).

The method used to describe the charge transport and exciton diffusion processes is the same as the one employed in earlier KMC simulations of phosphorescent OLEDs. ${ }^{19}$ Hopping of charge carriers is described by Miller-Abrahams (MA) rates, ${ }^{27}$ assuming a wavefunction decay length $\lambda=0.3 \mathrm{~nm}$ and a hopping attempt frequency to a first nearest neighbor equal to 3.3(0.33) $\times 10^{10} \mathrm{~s}^{-1}$ for holes (electrons). Using reduced electron hop rates mimics the effect of (unintentional) charge carrier trapping that is often observed for small-molecule materials (see, e.g., Ref. 28). We note that recent theoretical work has indicated that for small-molecule materials in amorphous thin films, the MA theory is often more appropriate than Marcus theory. ${ }^{29}$ For all materials, the energetic disorder is modeled assuming a spatially uncorrelated Gaussian density of states with a standard deviation of $\sigma=0.1 \mathrm{eV}$. Exciton generation (dissociation) is described as a hop of one carrier to (away from) a site at which a carrier of opposite polarity resides. The rates are equal to those for a regular hop, after including the effect of the exciton binding energy on the energy difference between the initial and final states ${ }^{19}$ so that no new parameters are involved. Exciton generation is assumed to lead to singlets and triplets at a ratio of 1:3. The exciton radiative and non-radiative decay rates are taken from Ref. 13 or estimated in the absence of literature data. The (reverse) intersystem crossing rates on $4 \mathrm{CzIPN}-\mathrm{Me}$ are taken to be $41(0.77) \times 10^{6} \mathrm{~s}^{-1}$. Exciton diffusion is described as resulting from a combination of thermally activated Förster and Dexter transfer, with a temperature dependence as described by the MA formula. For all materials, a Gaussian excitonic disorder of $0.05 \mathrm{eV}$ is assumed. As in Ref. 19, we use a Förster radius of (a)

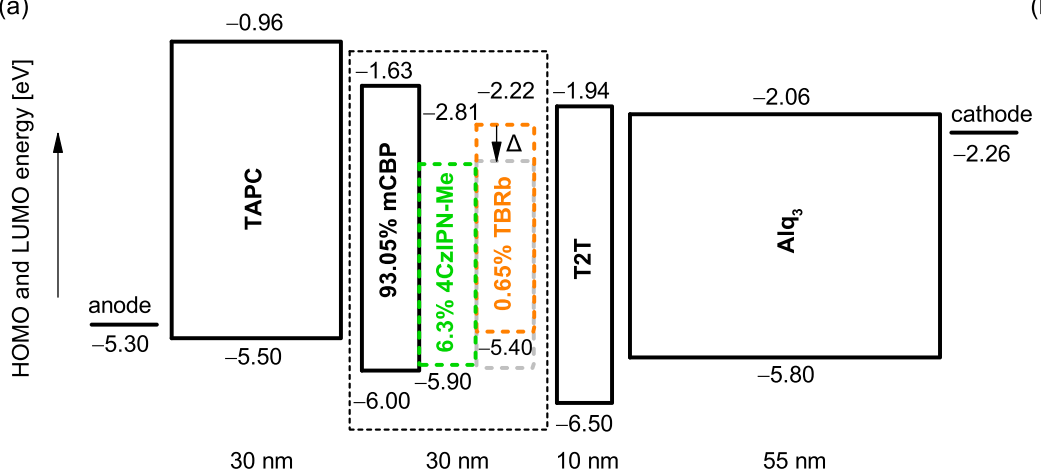

(b)

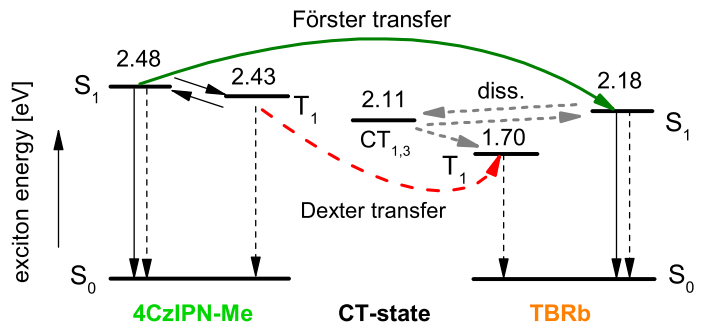

FIG. 1. (a) Layer and energy level structure of the HF-OLEDs studied. In the F-OLEDs and TADF-OLEDs, the EML does not include 4CzIPN-Me and TBRb, respectively. Our study also includes adapted HF-OLEDs within which the HOMO and LUMO energies of the fluorescent emitter are down-shifted over an energy $\Delta$. (b) Excitonic energy level diagram and the main excitonic transfer and dissociation processes. The full (dashed) thin arrows denote the (non)radiative decay. 
TABLE I. Material-specific parameters used for the KMC simulations. $E_{\text {HOMO }}$ and $E_{\text {LUMO }}$ were obtained as described in the main text and are given with respect to the vacuum level. The singlet (triplet) energies $E_{\mathrm{S}(\mathrm{T})}$ and the radiative (non-radiative) decay rates $k_{\mathrm{rad}}\left(k_{\mathrm{nr}}\right)$ were obtained from the references indicated or were given an assumed value.

\begin{tabular}{|c|c|c|c|c|c|c|}
\hline Material & $E_{\text {номо }}$ & $E_{\text {LUMO }}$ & $E_{\mathrm{S}}$ & $E_{\mathrm{T}}$ & $k_{(n r) r a d, S}$ & $k_{(n) r \text { rad, }, T}$ \\
\hline & $(\mathrm{eV})$ & $(\mathrm{eV})$ & $(\mathrm{eV})$ & $(\mathrm{eV})$ & {$\left[10^{6} \mathrm{~s}^{-1}\right]$} & {$\left[10^{6} \mathrm{~s}^{-1}\right]$} \\
\hline TAPC & $-5.50^{12}$ & -0.96 & $3.54^{31}$ & $2.95^{31}$ & $8(92)^{32,33}$ & $0(0.01)$ \\
\hline $\mathrm{mCBP}$ & $-6.00^{13}$ & -1.63 & $3.37^{12}$ & $2.90^{12}$ & $100(100)$ & $0(0.01)$ \\
\hline 4CzIPN-Me & $-5.90^{13,25}$ & $-2.81^{25}$ & $2.48^{13,25}$ & $2.43^{13,25}$ & $25(0)^{13^{\prime}}$ & $0(0.2)^{13}$ \\
\hline $\mathrm{TBRb}^{\mathrm{a}}$ & $-5.40^{13}$ & -2.22 & $2.18^{12,34}$ & 1.7 & $137(15.2)^{12,35}$ & $0(0.01)$ \\
\hline $\mathrm{T} 2 \mathrm{~T}$ & $-6.50^{13}$ & -1.94 & $3.56^{36}$ & $2.8^{36}$ & $100(100)$ & $0(0.01)$ \\
\hline $\mathrm{Alq}_{3}$ & $-5.80^{25}$ & $-2.06^{25}$ & $2.53^{25}$ & $2.1^{37}$ & $16.7(83.3)^{38}$ & $0(0.01)$ \\
\hline
\end{tabular}

${ }^{\mathrm{a}}$ In HF ${ }^{\star}-\mathrm{OLEDs}$, TBRb has been replaced by a hypothetical emitter with down-shifted HOMO and LUMO energies of $0.54 \mathrm{eV}$.

$1.5 \mathrm{~nm}$ for transfer between identical molecules. The rate for nearest-neighbor $(1 \mathrm{~nm})$ Dexter transfer [with an $\exp (-2 \mathrm{R} / \lambda)$ distance $(R)$ dependence] is taken close to the Förster transfer rate over $1.5 \mathrm{~nm}$, viz., $2.1 \times 10^{7} \mathrm{~s}^{-1}$. The Förster radius $R_{F, T A D F-F}$ for singlet transfer from $4 \mathrm{CzIPN}-\mathrm{Me}$ to $\mathrm{TBRb}$ is $7.4 \mathrm{~nm} .^{13}$ Förster-type exciton-polaron quenching and exciton-exciton annihilation processes are described with a $3.5 \mathrm{~nm}$ Förster radius, a value that can realistically describe $\mathrm{TPQ}^{21}$ and $\mathrm{TTA}^{30}$ in phosphorescent OLEDs. The end products of the SSA, STA, TSA, and TTA annihilation processes $(\mathrm{S}=$ singlet and $\mathrm{T}=$ triplet; the first exciton excites the second exciton) are assumed to be a single exciton, located at the site of the second exciton and with the same spin as that of the second exciton. Table I shows an overview of all electronic and excitonic energies used, as well as of the exciton radiative and non-radiative decay rates. A full overview of all simulation parameters used is given in the supplementary material, Sec. S1. Although most parameters used to describe the charge transport and exciton transfer processes are not yet material-specific, we regard this parameter set as a useful starting point that will elucidate the basic device operation.

Figure 2(a) shows a comparison between the simulated and experimental $\mathrm{J}(\mathrm{V})$ characteristics of the TADF-OLEDs and HF-
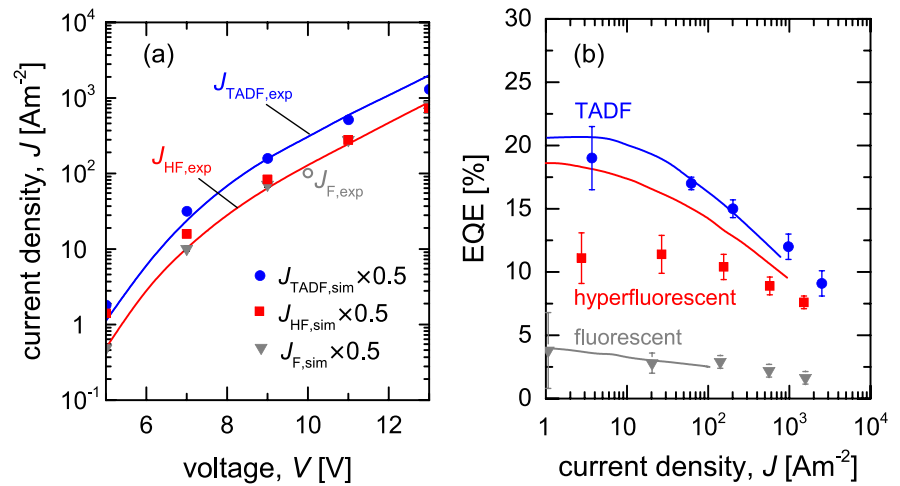

OLEDs. The slope of the curves and the reduction of $J$ when including TBRb are well described by the simulations. Although the absolute value is approximately a factor of two, we regard the agreement with experiment, obtained using a non-optimized value of the hopping attempt rate equal to that used in earlier studies (see above), as remarkably good in view of the realistic experimental reproducibility.

The current densities obtained for the F-OLEDs, for which from experiment only $\mathrm{J}(10 \mathrm{~V})$ is available (open gray circle), are very similar to those obtained for the HF-OLEDs.

In Fig. 2(b), the simulated and experimental quantum efficiencies (EQEs) are compared, assuming for all devices a light outcoupling efficiency of $25 \%$. For the F-OLEDs and TADFOLEDs, the agreement with experiment is fair. We note that for the TADF-OLEDs, the EQE at $5 \mathrm{~V}$ is already slightly reduced by quenching (see below, Fig. 3). Extrapolation suggests that in the low-V limit, the EQE is $\sim 20 \%$. However, within a simple localized-exciton model, the EQE is then only $16.0 \%$ (supplementary material, Sec. S2). Interestingly, we find that the EQE enhancement is due to an effective enhancement of the ISC and RISC rates as a result of exciton dissociation, leading to CT-excitons with the electron on 4CzIPN-Me and the hole on a neighbour mCBP or 4CzIPN-Me molecule,

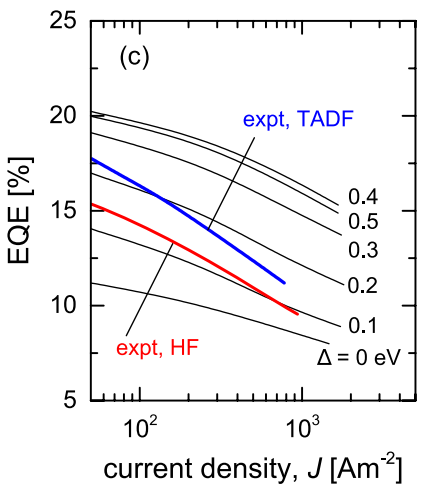

FIG. 2. (a) Voltage dependence of the current density, obtained from KMC simulations (symbols, shifted by a factor 2 to facilitate the comparison with experiment) and from experiment (curves and open circle ${ }^{13}$ ). (b) EQE as a function of the current density as obtained from KMC simulations (symbols), assuming a $25 \%$ light-outcoupling efficiency and from experiment (curves ${ }^{13}$ ). (c) EQE of HF-OLEDs with a varying energy shift $\Delta$, obtained from KMC simulations. Thick curve: experiment. (d) Dependence of the EQE from KMC simulations at 7 and $13 \mathrm{~V}$ on the TBRb concentration for the HF (squares) and HF* (diamonds) OLEDs. The red dashed line marks the fine-tuned concentration at which the experimental EQE was obtained. 


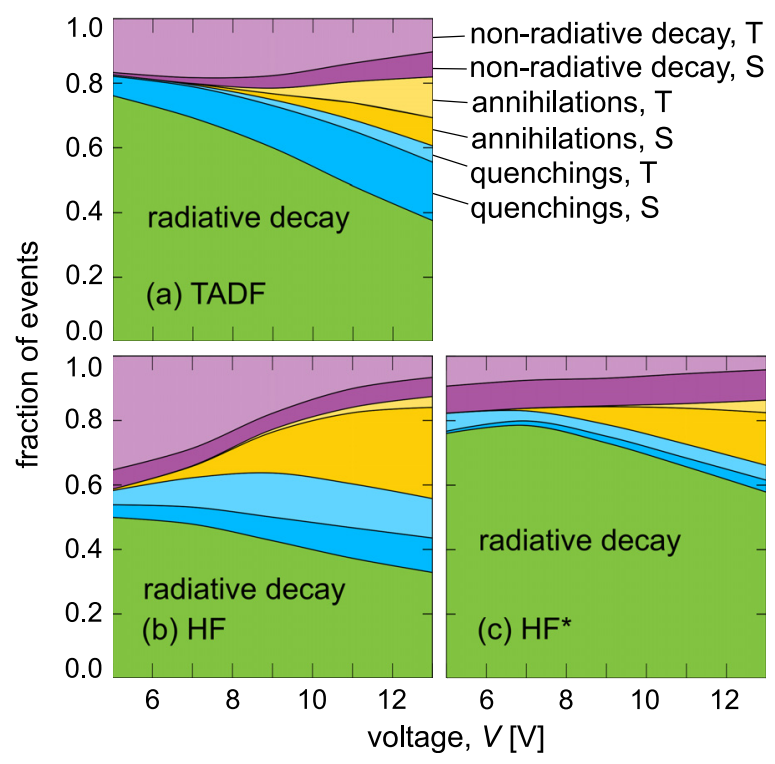

FIG. 3. Voltage dependence of the contributions to the efficiency roll-off in the TADF (a), HF (b), and HF*-OLEDs (c), for singlets (S) and triplets (T)

followed by singlet and triplet generation on $4 \mathrm{CzIPN}-\mathrm{Me}$ at a ratio of 1:3 (supplementary material, Sec. S3). This effect is highly sensitive to the binding energy of the excitons on 4CzIPN-Me.

When TBRb is added, the simulations predict that almost all emission $(\geq 90 \%)$ is due to TBRb-singlet decay (supplementary material, Sec. S6). Strong Förster transfer of singlets from the TADF-emitter is the main cause for the large population of TBRb singlets: additional simulations at $7 \mathrm{~V}$ in which all exciton transfer has been switched off, so that only direct electronic generation is possible, show quite weak TBRb-singlet emission ( 10\%). The total ratio of electrically generated excitons on $4 \mathrm{CzIPN}-\mathrm{Me}$ and TBRb at $7 \mathrm{~V}$ is approximately 75:25.

Consistent with experiment, the simulations predict a reduction of the EQE when TBRb is added. However, the reduction is larger than that found experimentally. The effect occurs already at low voltages so that it cannot be related to bimolecular loss processes. Furthermore, we find that the EQE reduction is not related to a strong change of the emission profile in the EML (supplementary material, Sec. S4). At low voltages, the profile is for both types of devices quite symmetric and peaked near the interfaces with the transport layers. By adding TBRb, the emission shifts slightly to the anode-side of the EML, as TBRb acts as a hole trap.

We find that the relatively small EQE obtained for the HF-OLEDs is due to singlet-to-triplet conversion on TBRb via CT-state formation and subsequent intersystem crossing [see Fig. 1(b)]. In order to study the role of this loss-mechanism, we have carried out simulations for hypothetical HF-OLEDs with an equal HOMO and LUMO energy shift $\Delta$ [see Fig. 1(a)] while keeping all other parameters unchanged. This increases the CT-state energy, so that thermal dissociation of TBRb-singlets becomes less likely. Figure 2(c) shows that the EQE depends sensitively on $\Delta$ and that already for a shift of $0.1-0.15 \mathrm{eV}$, a fair agreement with the experimental EQE is obtained. The experimental roll-off is then only slightly stronger than that obtained from the simulations. Interestingly, the simulations suggest that the EQE could be further increased, to values larger than that obtained for the TADF-OLED, by using an emitter with $\Delta \approx 0.45 \mathrm{eV}$. This finding emphasizes that for realizing the full potential of HF-OLEDs, fluorescent emitters with carefully selected HOMO and LUMO levels should be used. We tentatively attribute the decrease in the EQE beyond $\Delta \cong 0.45 \mathrm{eV}$ (see supplementary material, Sec. $\mathrm{S} 5)$ to the conversion of TBRb-singlets to TBRb-triplets via the formation of [TBRb(electron)-mCBP(hole)]-type CT states, followed by intersystem crossing. We note that the existence of the $4 \mathrm{CzIPN}$-TBRb CT-state is inferred from the KMC simulations and is not based on a priori knowledge of this state from experiment. It would be of interest to study the formation of this state spectroscopically, e.g., using time-delayed luminescence experiments.

A potential loss channel is Dexter transfer from the TADF emitters to the TBRb molecules. ${ }^{13}$ However, when that process is disabled, we find no significant change in the efficiency. Consistent with that finding, Fig. 2(d) shows that in the absence of an energy level shift ( $\Delta=0 \mathrm{eV}$, nominal HF-OLEDs), the EQE decreases already immediately after the addition of TBRb, for TBRb concentrations for which Dexter transfer is not yet effective. For hypothetical $\mathrm{HF}^{*}$-OLEDs with an energy level shift of $\Delta$ $=0.54 \mathrm{eV}$ (such that a symmetric alignment of the HOMO and LUMO of the TADF emitter and TBRb is obtained and close to the optimum), Fig. 2(d) shows that the EQE displays a maximum around $0.5 \mathrm{~mol}$. \%, close to the fine-tuned experimental concentration of $0.65 \mathrm{~mol}$. \%. We find that the maximum may be viewed as a result of an increase in the EQE for small TBRb concentrations due to Förster transfer of more long-lived singlets on 4 CzIPN-Me to TBRb, combined with a decrease for high $\mathrm{TBRb}$ concentrations due to an increased fraction of excitons which are generated directly on TBRb, of which $75 \%$ is generated in the triplet state. The simulations also reveal the sensitivity to $R_{F, T A D F-F}$. A reduction from 7.4 to $3.7 \mathrm{~nm}$, e.g., reduces the fraction of excitons on the TBRb to only $\sim 65 \%$ (instead of $\sim 90 \%$ for the HF-OLEDs). The EQE is only reduced by $\sim 1 \%$, for the entire voltage range studied, as the emission from the TADF emitter is also quite efficient.

Figures 3(a)-3(c) show the voltage dependence of the contributions of various mechanisms to the efficiency roll-off. In the low-voltage limit, non-radiative exciton decay is the only loss mechanism. Around 5V, exciton-polaron quenching already contributes, whereas at higher voltages, exciton-exciton annihilation also contributes. In the HF-OLEDs, the contribution due to non-radiative triplet decay is much larger than that in the TADF-OLEDs. Consistent with the dissociation-mechanism discussed above, this loss occurs predominantly on the TBRb molecules, as may be seen from a further breakdown of the loss in material-specific contributions (supplementary material, Sec. S6). This also explains the large contribution due to annihilation of singlets which is found at high voltages for the HF-OLED, which is due to singlet-triplet annihilation on the TBRb emitter. 
Figure 3(c) shows that these loss-channels, related to triplets on the TBRb molecules, are strongly reduced in the $\mathrm{HF}^{*}$-OLEDs.

In conclusion, we find that KMC simulations can provide a fair description of the current density and EQE roll-off of prototypical TADF-OLEDs and HF-OLEDs, in the latter case, after adopting a slight $(\sim 0.15 \mathrm{eV})$ energy level shift. The EQE of HFOLEDs is sensitively affected by the formation of charge-transfer states between the fluorescent and TADF molecules. Fully exploiting the potential of hyperfluorescent OLEDs thus requires not only optimizing the fluorescent emitter concentration but also carefully adapting the energy levels of the fluorescent emitter to those of the TADF emitter and the host material. This study shows how KMC simulations can be used to identify the most relevant loss channels and to design more efficient layer stacks.

See supplementary material for an overview of the simulation parameters (S1), an expression for the luminescence efficiency for an ensemble of TADF emitters (S2), an analysis of CT-state formation (S3), the emission profiles (S4), the effect of the energy level shift on the EQE of the HF-OLEDs (S5), and the material-specific contributions to the excitonic processes (S6).

We thank X. de Vries and Chr. Hauenstein for useful discussions.

\section{REFERENCES}

${ }^{1}$ A. Endo, M. Ogasawara, A. Takahashi, D. Yokoyama, Y. Kato, and C. Adachi, Adv. Mater. 21, 4802 (2009).

${ }^{2}$ K. Goushi, K. Yoshida, K. Sato, and C. Adachi, Nat. Photonics 6, 253 (2012).

${ }^{3}$ H. Uoyama, K. Goushi, K. Shizu, H. Nomura, and C. Adachi, Nature 492, 234 (2012).

${ }^{4}$ F. B. Dias, K. N. Bourdakos, V. Jankus, K. C. Moss, K. T. Kamtekar, V. Bhalla, J. Santos, M. R. Bryce, and A. P. Monkman, Adv. Mater. 25, 3707 (2013).

${ }^{5}$ C. Adachi, Jpn. J. Appl, Phys., Part 153, 60101 (2014).

${ }^{6}$ K. Sato, K. Shizu, K. Yoshimura, A. Kawada, H. Miyazaki, and C. Adachi, Phys. Rev. Lett. 110, 247401 (2013).

${ }^{7}$ X. Cai and S.-J. Su, Adv. Funct. Mater. 28, 1802558 (2018).

${ }^{8}$ T.-L. Wu, M.-J. Huang, C.-C. Lin, P.-Y. Huang, T.-Y. Chou, R.-W. ChenCheng, H.-W. Lin, R.-S. Liu, and C.-H. Cheng, Nat. Photonics 12, 235 (2018).

${ }^{9}$ M. A. Baldo and S. R. Forrest, Phys. Rev. B 62, 10958 (2000).

${ }^{10}$ M. A. Baldo, C. Adachi, and S. R. Forrest, Phys. Rev. B 62, 10967 (2000).
"C. Murawski, K. Leo, and M. C. Gather, Adv. Mater. 25, 6801 (2013).

${ }^{12}$ H. Nakanotani, T. Higuchi, T. Furukawa, K. Masui, K. Morimoto, M. Numata, H. Tanaka, Y. Sagara, T. Yasuda, and C. Adachi, Nat. Commun. 5, 4016 (2014).

${ }^{13}$ T. Furukawa, H. Nakanotani, M. Inoue, and C. Adachi, Sci. Rep. 5, 8429 (2015).

${ }^{14}$ L. Bergmann, D. M. Zink, S. Bräse, T. Baumann, and D. Volz, Top. Curr. Chem. 374, 22 (2016).

${ }^{15}$ D. Volz, J. Photon. Energy 6, 020901 (2016).

${ }^{16}$ M. Y. Wong and E. Zysman-Colman, Adv. Mater. 29, 1605444 (2017).

${ }^{17}$ Z. Yang, Z. Mao, Z. Xie, Y. Zhang, S. Liu, J. Zhao, J. Xu, Z. Chi, and M. Aldred, Chem. Soc. Rev. 46, 915 (2017).

${ }^{18}$ W. Song and K.-S. Yook, J. Ind. Eng. Chem. 61, 445 (2018).

${ }^{19}$ H. van Eersel, P. A. Bobbert, R. A. J. Janssen, and R. Coehoorn, Appl. Phys. Lett. 105, 143303 (2014).

${ }^{20}$ R. Coehoorn, H. van Eersel, P. A. Bobbert, and R. A. J. Janssen, Adv. Funct. Mater. 25, 2024 (2015).

${ }^{21}$ M. Mesta, H. van Eersel, R. Coehoorn, and P. A. Bobbert, Appl. Phys. Lett. 108, 133301 (2016).

${ }^{22}$ H. van Eersel, P. A. Bobbert, R. A. J. Janssen, and R. Coehoorn, J. Appl. Phys. 119, 163102 (2016).

${ }^{23}$ See http://simbeyond.com for "Simbeyond B.V."

${ }^{24}$ M. Knupfer, Appl. Phys. A 77, 623 (2003).

${ }^{25}$ H. Yoshida and K. Yoshizaki, Org. Electron. 20, 24 (2015).

${ }^{26}$ The exciton binding energy of $4 \mathrm{CzIPN}-\mathrm{Me}$ is assumed to be very similar to that of $4 \mathrm{CzIPN}$, studied in Ref. 25.

${ }^{27}$ A. Miller and E. Abrahams, Phys. Rev. 120, 745 (1960).

${ }^{28}$ M. Mesta, M. Carvelli, R. J. de Vries, H. van Eersel, J. J. M. van der Holst, M. Schober, M. Furno, B. Lüssem, K. Leo, P. Loebl, R. Coehoorn, and P. A. Bobbert, Nat. Mater, 12, 652 (2013).

${ }^{29}$ X. de Vries, P. Friederich, W. Wenzel, R. Coehoorn, and P. A. Bobbert, Phys. Rev. B 97, 075203 (2018).

${ }^{30}$ A. Ligthart, X. de Vries, L. Zhang, M. C. W. M. Pols, P. A. Bobbert, H. van Eersel, and R. Coehoorn, Adv. Funct. Mater. 28, 1804618 (2018).

${ }^{31}$ V. Jankus, P. Data, D. Graves, C. McGuinness, J. Santos, M. R. Bryce, F. B. Dias, and A. P. Monkman, Adv. Funct. Mater. 24, 6178 (2014).

${ }^{32}$ Y. Seino, H. Sasabe, Y. Pu, and J. Kido, Adv. Mater. 26, 1612 (2014).

${ }^{33} \mathrm{~K}$. Hensel and H. Bässler, Adv. Mater. Opt. Electron. 1, 179 (1992).

${ }^{34}$ Y.-S. Wu, T.-H. Liu, H.-H. Chen, and C. H. Chen, Thin Solid Films 496, 626 (2006).

${ }^{35}$ W. Choy, Y. Wu, C. Chen, and K. Cheah, Appl. Phys. A 81, 517 (2005).

${ }^{36}$ H.-F. Chen, S.-J. Yang, Z.-H. Tsai, W.-Y. Hung, T.-C. Wang, and K.-T. Wong, J. Mater. Chem. 19, 8112 (2009).

${ }^{37}$ H. D. Burrows, M. Fernandes, J. Seixas de Melo, A. P. Monkman, and S. Navaratnam, J. Am. Chem. Soc. 125, 15310 (2003).

${ }^{38}$ N. Matsumoto, M. Nishiyama, and C. Adachi, J. Phys. Chem. C 112, 7735 (2008). 